\title{
IMPLICACIONES TERRITORIALES DE UNA GRAN OBRA HIDRÁULICA: EL EMBALSE DEL TRANCO (CABECERA DEL GUADALQUIVIR)
}

\author{
Eduardo Araque Jiménez \\ Área de Análisis Geográfico Regional \\ Universidad de Jaén
}

\section{RESUMEN}

Situado en la cabecera del Guadalquivir, el embalse del Tranco fue durante muchos años el de mayor capacidad de almacenamiento de agua de toda Andalucía. Sus aportaciones resultaron fundamentales para el sostenimiento del regadío en el gran valle bético, al tiempo que con sus aguas pudo generarse una parte de la energía eléctrica que se precisaba para la modernización del aparato productivo andaluz y la mejora de las condiciones de vida en multitud de hogares en el valle del Guadalquivir. Frente a estas perspectivas tan halagüeñas, las aguas embalsadas en el Tranco apenas tuvieron repercusiones socioeconómicas positivas para la Sierra de Segura. Las expropiaciones masivas a las que dio origen tanto la construcción del embalse como la repoblación forestal que lo acompañó, propiciaron la emigración masiva de centenares de vecinos, muchas veces en condiciones de extrema precariedad. Por otro lado, las aguas del Tranco nunca se utilizaron para la expansión del regadío por algunos de los fértiles valles próximos al embalse, ni la electricidad generada a pie de presa llegó a los hogares serranos, que siguieron careciendo de este servicio durante muchos años.

Palabras clave: Embalse del Tranco, regadío, producción de electricidad repoblación forestal, roturación de los montes.

\section{ABSTRACT}

The reservoir of El Tranco, located in Guadalquivir River headwaters, was the one with the larger capacity of storage of water in Andalusia. Its contribution has been essential to support the irrigation in the extensive betic valley, besides its water make possible the generation of electrical energy that was necessary to modernize the Andalusian economic system and the improvement of standard of living in a lot of homes in Guadalquivir valley. However, these promising perspectives did not have scarcely positive socio-economic repercussions in Segura Mountain Range. The massive compulsory purchases due to the building of reservoir and the joined reforestation brought about the migration of hundreds of inhabitants, with poor conditions in a lot of times. Otherwise, the water accumulated 
in the reservoir of El Tranco was never used for the expansion of irrigation along some of fertile valleys near to it, either the electricity generated in the dam arrived to mountain homes, which lacked of this supply during a lot of years.

Key words: Reservoir of El Tranco, irrigation, generation of electrical energy, reforestation, plough up of forests

\section{Introducción}

Situado en la cabecera del Guadalquivir, a medio centenar de kilómetros de su nacimiento (Cañada de las Fuentes), el embalse del Tranco figuró durante muchos años como uno de los de mayor capacidad de almacenamiento de agua de España, y hasta 1969, en que fue desplazado por el embalse de Iznajar $\left(981 \mathrm{Hm}^{3}\right)$, como el de mayor volumen de embalse de Andalucía (Mapa 1). Con una capacidad de almacenamiento de $500 \mathrm{Hm}^{3}$, la construcción de esta gran obra hidráulica se había contemplado en el plan de 1902, si bien por las mismas razones económicas que abortaron la inmensa mayoría de los pantanos y canales de riego que incluía aquel documento, el inicio de las obras no se produjo hasta casi tres décadas después. Concebido como una obra de regulación hidráulica primordial del cauce del gran río bético, con la entrada en funcionamiento del Tranco se abrían nuevas perspectivas de desarrollo para el conjunto del valle del Guadalquivir, ligadas, por un lado, al incremento de la producción agrícola en las miles de hectáreas transformadas en regadío gracias a las aguas embalsadas y, por otro, a la industrialización de los nuevos cultivos que debían implantarse en las feraces vegas del río.

Frente a esta perspectiva tan halagüeña, a los municipios de la Sierra de Segura que acogían esta grandiosa infraestructura hidráulica se les adivinaba un porvenir mucho más incierto, plagado de negros augurios. Es cierto que mientras se ejecutaron las obras, el pantano se convirtió en el más poderoso motor de empleo local jamás conocido, capaz de erradicar el extremado paro crónico que habían padecido secularmente los habitantes de estas tierras serranas. Pero no lo es menos que, una vez finalizadas las obras, aquel espejismo se disipó para siempre y toda la comarca se vio envuelta en la misma dinámica de abandono y marginación que asoló a la montaña mediterránea andaluza durante la segunda mitad del siglo XX (Rodríguez Martínez, 1981). Ni el agua embalsada, ni la energía eléctrica generada a pie de presa favorecieron el desarrollo endógeno de este rincón de la provincia de Jaén que ya en el momento en que comenzaron las obras del pantano fue bautizado por Luis Bello como «las otras Hurdes» (Bello, 1929); una referencia clara y directa al paradigma de la pobreza española en aquellos momentos, al estado de miseria y abandono en el que les había tocado vivir a la inmensa mayoría de sus habitantes durante siglos.

La construcción del pantano, en todo caso, provocó una serie de cambios territoriales y paisajísticos a los que apenas se ha prestado atención hasta el momento. Además de alterar el régimen tradicional de las conducciones fluviales de madera que descendían por el Guadalquivir, bajo las aguas del embalse quedaron sepultadas para siempre centenares de viviendas y unas fecundas tierras de cultivo que sus habitantes habían cuidado con esmero durante generaciones a fin de garantizarse su subsistencia y asegurar la de sus herederos. Por otra parte, la repoblación forestal de la cuenca de alimentación del embalse que se abordó mientras concluían las obras de cierre del muro de la presa, ocasionó un tremendo problema social al engullir a multitud de pequeñas roturaciones agrícolas dispersas por los montes desde mucho tiempo antes. Es verdad que con ello se quería salvaguardar el vaso del pantano de los perniciosos efectos de la erosión, que amenazaba con dejar inservibles en poco tiempo unas obras que habían resultado enormemente gravosas. Pero no es menos 
cierto que a quienes ocupaban todas esas tierras de cultivo se les condenó irremediablemente a la emigración, en muchos casos sin recibir a cambio una mínima contraprestación económica por los bienes que habían perdido.

La desaparición de este singular sistema de poblamiento serrano vino acompañada de profundos cambios paisajísticos inducidos por la intensidad de la acción reforestadora, preludio de otros cambios funcionales que empezarían a materializarse poco después con la creación del Coto Nacional de Caza de las Sierras de Cazorla y Segura (1960) y, más tarde, con la declaración del Parque Natural de las Sierras de Cazorla, Segura y Las Villas (1986). En ambos casos la presencia del embalse y del extenso manto pinariego que lo envolvía, resultaron determinantes para el establecimiento de semejantes figuras de protección de la naturaleza, a partir de las cuales se inició una lenta pero paulatina vinculación de los montes a las funciones recreativas, absolutamente dominantes en estos momentos.

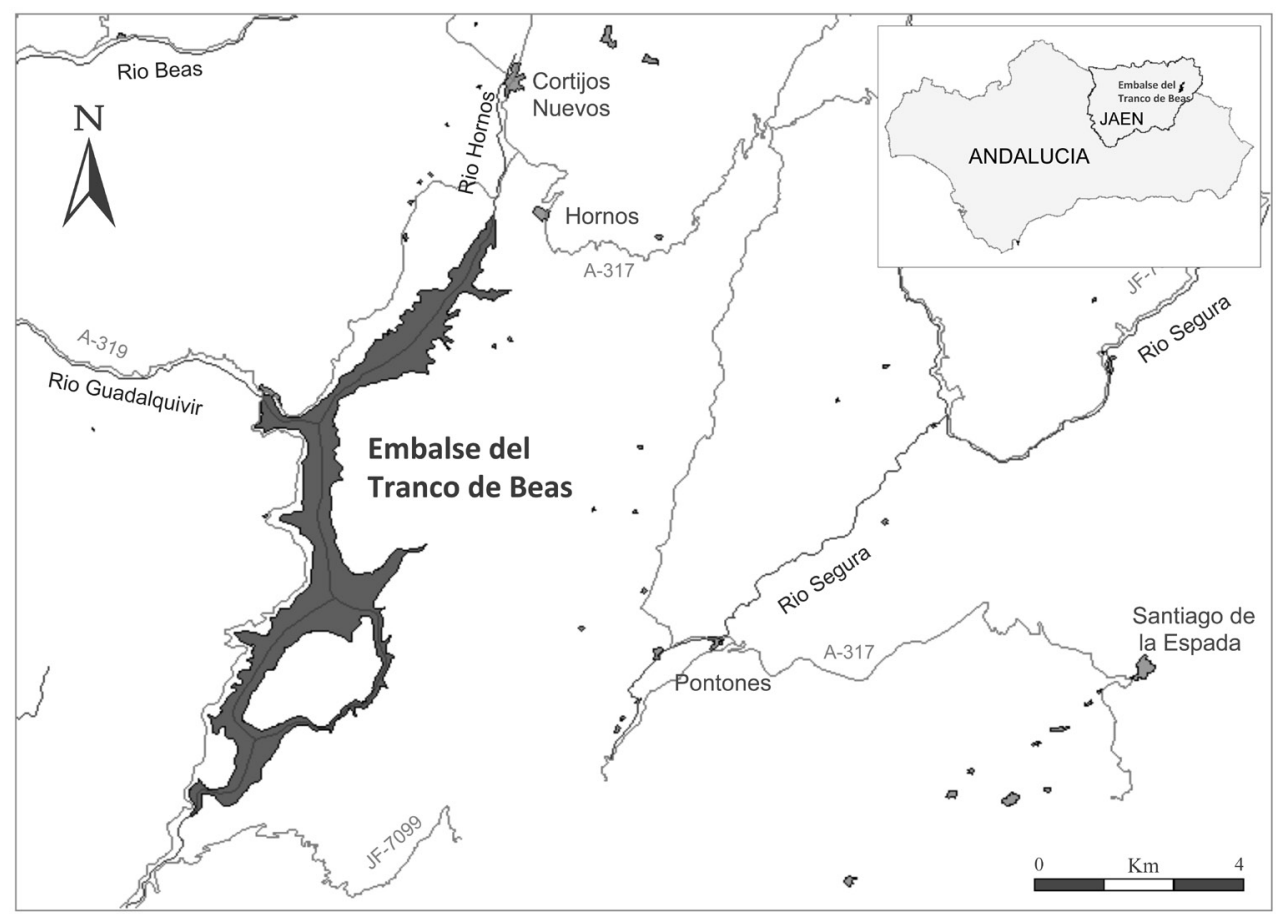

MAPA 1. Localización del embalse del Tranco.

\section{El canal de la Loma y el embalse del Tranco}

En la extensa propuesta de más de doscientas obras que incluía el «Plan de obras públicas» de $1902^{1}$, conocido también como «Plan general de canales de riego y pantanos», figuraba con el número 37 la construcción del canal de la Loma de Úbeda y del pantano

1 Real decreto de 25 de abril de 1902. Gaceta de Madrid. 27 de abril de 1902. También puede verse el Plan en Revista de Obras Públicas. 1902. Nº 1388. Págs. 386-388; Nº 1389. Págs. 404-406; Nº 1390. Págs. $423-$ 425 . 
del Tranco de Beas, destinadas ambas a dar riego a 10.000 has. de los términos jiennenses de Villanueva del Arzobispo, Villacarrillo, Torreperogil, Úbeda y Baeza. El pantano se construiría en la cerrada del conocido como Tranco de Monzoque (Lozano Muñoz, 1867), mientras que el canal partiría de un punto situado a dos kilómetros aguas abajo de la cerrada, y aprovechando la fuerza de la gravedad llevaría el agua hasta los sedientos campos de cultivo situados en la cara sur de la comarca de La Loma.

Por distintas causas que ya han sido suficientemente estudiadas (Gil Olcina, 2001), la mayor parte de esas obras nunca llegaron a abordarse, o bien se abordaron mucho más tarde en coyunturas económicas menos críticas que la del tránsito de los siglos XIX al $\mathrm{XX}$. Entre las excepciones se cuentan las dos obras que nos ocupan, seguramente porque ninguna de ellas formaba parte de lo que Manuel Lorenzo Pardo, al analizar aquel Plan, dio en calificar como «una copiosa cosecha de iniciativas de la más variada procedencia y la más variable garantía» (citado en Gil Olcina, 2001). En efecto, la inclusión de estas obras en el Plan no era fruto, en modo alguno, de la casualidad o la improvisación de los Ingenieros de caminos que las habían propuesto, sino que respondían a una vieja aspiración de buena parte de los propietarios jiennenses del valle del Guadalquivir, que ya venían demandándola desde mediados del siglo XIX (Speyser, 1858; Mesa, 1864; Anguis, 1933).

Con antelación al inicio de las obras, no obstante, se barajaron distintas alternativas en forma de proyectos, en todos los cuales, hasta 1925, se contemplaban la construcción de las dos obras, pantano y canal. Ese año, durante la celebración en Jaén de una Asamblea magna provincial (Araque Jiménez y Gallego Simón, 2007), se presentó una nueva propuesta por parte de un Ingeniero que trabajaba para la compañía eléctrica Mengemor, en la que ya no se hacía referencia al canal de La Loma. Finalmente fue ésta la que acabó imponiéndose en 1933 (Anguis Diaz, 1933).

En cuanto al pantano el Tranco, a mediados del mes de agosto de 1927 vio la luz el Real decreto-ley ${ }^{2}$ mediante el cual se aprobaba el proyecto y se autorizaba a la división hidráulica del Guadalquivir a poner en marcha las obras. El proyecto inicial al que se refería la norma lo había redactado Antonio del Aguila y contemplaba, entre otras cosas, una sustancial ampliación de la capacidad de almacenamiento de agua que se había previsto tradicionalmente, situándola en $500 \mathrm{Hm}^{3}$. El proyecto definitivo de construcción se redactó por Florentino Briones, que fue quien dirigió los trabajos de construcción hasta casi su finalización, siendo reemplazado por José Luis González Muñiz.

Antes de que se iniciaran las obras de construcción del muro de la presa, mientras se redactaban los proyectos definitivos de los diferentes elementos de la misma, se puso en marcha el proceso de expropiación de las tierras, enseres y demás bienes inmuebles que quedaban por debajo de la cota de máximo embalse. Dada la dimensión de la zona afectada (1.800 has.), esta tarea resultó ardua y compleja, además de dilatarse en el tiempo, dada la gran cantidad de expedientes que tuvieron que sustanciarse. La ocupación histórica de los valles de los ríos Guadalquivir y Hornos había dado origen a miles de propiedades en forma de pequeñas huertos agrícolas dedicados exclusivamente a asegurar la subsistencia de sus propietarios y la de sus familias. Todos ellos debían abandonarse con celeridad so pena de verse anegados por las aguas.

Al mismo tiempo que se resolvía el farragoso problema que planteaban las numerosas actas de expropiación, comenzaron los preparativos para el levantamiento del muro de la presa; una obra de envergadura cuya mayor dificultad no estribaba tanto en las complicaciones técnicas del proyecto (el muro alcanzaba una altura de 95 metros desde los cimientos y tenía una anchura de coronación de 5 metros, siendo su volumen total de $230.000 \mathrm{~m}^{3}$ ), sino

2 Real decreto-ley de 15 de agosto de 1927. Gaceta de Madrid. 20 de agosto de 1927. 
en el extremo aislamiento de la cerrada sobre la que había decidido establecerse la presa, completamente apartada de las principales vías de comunicación provinciales. Para sortear un escollo de tal relevancia fue preciso construir un camino de servicio que conectaba el muro de la presa con la carretera nacional Córdoba-Valencia a la altura de Villanueva del Arzobispo, en plena Loma de Úbeda. Esta vía de acceso, de 26 kilómetros de longitud, empezó a construirse a mediados de 1928 y a finales de 1929 se produjo su recepción por la Confederación Sindical Hidrográfica del Guadalquivir, de manera que desde ese momento pudieron empezar a recibirse a pie de obra las máquinas y materiales precisos para poder comenzar los trabajos.

Por otro lado, a principios de 1929 se iniciaron los preparativos para el tendido de una línea eléctrica de 42 kilómetros de longitud que comunicaba la central de Olvera, en el cauce del Guadalimar, con las obras de la presa. El tendido se completó con la instalación de una pequeña subestación de transformación al pie de la presa que permitía aplicar la electricidad tanto a la iluminación de las zonas de trabajo como al movimiento de la maquinaria.

Simultáneamente, se procedió a la construcción de un pequeño poblado para residencia de los trabajadores que se empleaba en las obras, cuya finalización tuvo lugar a mediados de 1930. Localizado en la margen derecha del muro de la presa, estaba integrado por varios grupos de viviendas destinadas al cuerpo técnico y por numerosos barracones donde se albergaban los obreros. En algunos momentos llegaron a residir en el poblado hasta 1.000 personas, lo que obligó a la Confederación Hidrográfica del Guadalquivir, propietaria del mismo, a dotarlo de toda clase de equipamientos e instalaciones para atención de tan numerosa colonia.

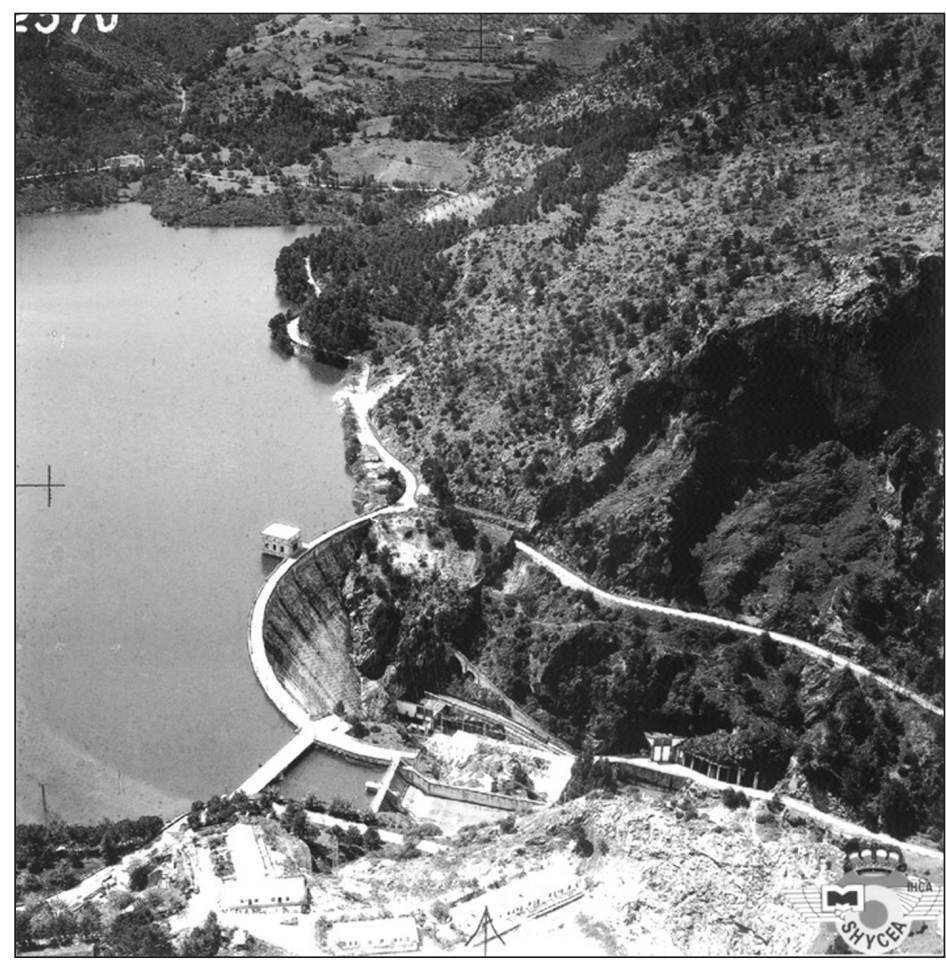

Fото 1. Vista aérea del embalse del Tranco. 
La creación de toda esta infraestructura permitió dar comienzo a los trabajos de excavación, que se pusieron en marcha en los primeros días de 1930. A estos le siguieron los de hormigonado en 1931, de manera que en 1934 había quedado prácticamente terminado el muro de la presa, tal y como señala Florentino Briones, director de las obras de ejecución (Briones Blanco, 1946). A finales de 1935 se sacaron a concurso el resto de las obras, esto es, la pantalla general de impermeabilización de la presa, la torre de toma, la construcción y montaje de las obras automáticas del pantano y los desagüies reguladores. Sin embargo el clima político y económico del momento no sólo impidió que se fallaran tales concursos sino que se paralizaron por completo las obras.

Hubo que esperar a que finalizara la guerra civil para que las obras recibieran un impulso definitivo. Como era preceptivo, lo primero que se hizo, en agosto de 1939, fue anular los concursos que se habían anunciado poco antes de comenzar la guerra civil. Inmediatamente después de ésta, entre finales de 1939 y los primeros meses de 1940, se volvieron a anunciar todos ellos aunque ahora con la incorporación de alguno nuevo como el de la impermeabilización de la ladera izquierda de la presa, que se consideró absolutamente imprescindible después de realizar un profundo estudio geológico y comprobar que las filtraciones podían dar al traste con toda la obra (Aldaz Muguiro, 1945). La adjudicación a las dos empresas que resultaron ganadoras de los distintos concursos (Maquinista y Fundiciones del Ebro y Agromán) tuvo lugar durante la segunda mitad de 1940, de manera que, tras la ejecución de las obras, en 1944 se cerraron las compuertas, comenzando el pantano a partir de aquel momento a embalsar agua. Finalmente el embalse se inauguró oficialmente a finales de mayo de 1946 en presencia del jefe del Estado.

\section{Conducciones fluviales de madera}

El inicio de las obras de la presa del Tranco supuso una seria alteración de las condiciones bajo las cuales se habían desenvuelto hasta entonces las conducciones fluviales de madera; una actividad profundamente arraigada en las Sierras de Segura y Cazorla que desde finales del siglo XIX había conocido un desarrollo espectacular, generando un gran número de empleos debido a la gran cantidad de madera movilizada. Aunque ya a comienzos de los años treinta el número de piezas transportado por el Guadalquivir había decaído considerablemente, era preciso adoptar todas las precauciones pertinentes para que el muro no se viera afectado como consecuencia del paso de la maderada. Como ya se ha expuesto en otro lugar (Araque Jiménez, 2007), en 1931 la Confederación Hidrográfica del Guadalquivir advirtió a los responsables de las conducciones que podía proceder en cualquier momento a la suspensión del tráfico maderero si llegaba a comprobar que éste entrañaba algún tipo de riesgo para las obras de establecimiento del muro de la presa. Para salvar este obstáculo, se ofrecía a los madereros la posibilidad de efectuar el desembarque de las piezas aguas arriba de la presa, continuando el transporte por vía terrestre a través de la carretera que conectaba con Villanueva del Arzobispo.

Tras la reactivación del tráfico fluvial que se registró al finalizar la guerra civil, motivado por el destacado papel que se asignó a estas sierras a la hora del aprovisionamiento maderero de la recién creada RENFE (Araque Jiménez, 2009 a), no hubo más remedio que arbitrar nuevas soluciones pues si importante resultaba la protección del muro de la presa, mucho más lo era el abastecimiento de madera a la estratégica tarea de reconstrucción del tejido ferroviario, máxime en un contexto de escasez generalizada de combustible que impedía transportar la madera por medios mecánicos. Para solventar el problema planteado fue preciso construir en la margen izquierda del muro de la presa un elevador de madera, único en su género en España, que entró en funcionamiento en 1944, cuando 
empezaban a intensificarse las cortas y a multiplicarse el número de piezas transportado por el Guadalquviir. El artilugio estaba compuesto por una cinta sin fin formada por dos cadenas articuladas que se movían a lo largo de un plano inclinado, a través del cual ascendían las traviesas hasta la coronación de la presa. Unas garras permitían sujetar cada una de las piezas en su ascensión, mientras que una malla, que cubría la cinta en toda su extensión, evitaba su caída al vacío. La capacidad de elevación de la cinta era de 8.000 traviesas, o de otra clase de piezas de similar volumen y dimensión, en una jornada de dieciséis horas, aunque podía forzarse su funcionamiento hasta conseguir un rendimiento superior (Briones Blanco, 1946).

Superado el muro de la presa, las piezas se devolvían al cauce del Guadalquivir a través de un largo túnel excavado en la parte opuesta de la pared a la que se encontraba el elevador. Esta operación comportaba un riesgo mucho mayor que el de la elevación toda vez que el gran desnivel que tenían que salvar las piezas les hacía alcanzar una gran velocidad en su descenso, y como consecuencia del rozamiento con la base y las paredes del túnel, algunas de ellas acababan incendiándose. Para sortear este inconveniente, continuamente se inyectaba agua al túnel con el fin de enfriar la madera en su caída. Al final de la larga rampa existía una pequeña balsa alimentada con las aguas procedentes del canal de desagüe del pantano, que no sólo amortiguaba la caída de las piezas y evitaba su deterioro sino que servía también para enfriar definitivamente la madera antes de devolverla al cauce del Guadalquivir.

A medida que las aguas embalsadas en el pantano fueron alcanzando un mayor nivel, las dificultades para la navegación se acrecentaron puesto que las piezas podían acabar dispersándose por la extensa lámina de agua. Para evitar que esto sucediera, en 1945 se construyó un gran canal sobre las aguas del embalse, compuesto por dos grandes hileras de traviesas que alcanzaban una longitud de 20 kilómetros. De este modo, cuando las traviesas entraban en el canal se dirigían directamente hasta la base del elevador, donde eran recogidas.

La aceleración de esta maniobra se consiguió arrastrando mediante canoas los grandes «reos» que se formaban al enlazar unas traviesas con otras. Hasta 25.000 traviesas de una sola vez llegaron a arrastrar estas embarcaciones trabajando ininterrumpidamente durante 16 horas (Tresaco Calvo, 1968). Las dos canoas que funcionaron durante estos años en las aguas del embalse del Tranco eran, en realidad, barcas de remos a las que los propios Ingenieros encargados de la explotación forestal habían acoplado los motores de dos viejos camiones Chevrolet (Tresaco Calvo, 1968). Esto prueba la enorme escasez de medios materiales que se registró durante estos años, al tiempo que pone de manifiesto el espíritu de superación de unos equipos técnicos que en todo este tiempo desarrollaron su labor en las condiciones más adversas que uno se pudiera imaginar.

\section{El regadío en el valle del Guadalquivir}

Con tan importante reserva de agua en la cabecera del Guadalquivir ya podían afrontarse con todas las garantías las crecientes necesidades hídricas de los cultivos que habían empezado a expandirse por la porción intermedia y baja del valle, aguas abajo de Córdoba. Entre ellos, el más exigente desde el punto de vista hídrico era el arroz. Su implantación y desarrollo fue muy tímido en la década de los años veinte pero ya en los años cuarenta ocupaba más de 3.000 has. en las Marismas del Guadalquivir (Calatayud Giner, 2002), con lo cual los aportes del Tranco comenzaban a resultar imprescindibles para asegurar el cultivo. Lo mismo sucedía con los frutales implantados en las vegas cordobesas, cuyas demandas hídricas eran de menor entidad pero igualmente necesarias para garantizar la prosperidad del cultivo. 
Hasta comienzos de los años cincuenta no se dio a conocer el primer gran proyecto de transformación en regadío de las sedientas tierras jiennenses. Se impulsó dicho proyecto a través del «Plan de obras, colonización, industrialización y electrificación de la provincia de Jaén», aprobado mediante Ley en 1953, en el cual se contemplaba, siguiendo las directrices marcadas por la política de colonización agraria del primer franquismo (Araque Jiménez et al., 2006), la transformación en regadío de las vegas próximas al Guadalquivir a lo largo de casi todo su recorrido por la provincia jiennense. Era esta la única forma de compensar, al menos en parte, a los defraudados agricultores de la comarca de La Loma de Ubeda después de haberse esfumado el proyecto decimonónico del canal de riego, y también de atender las aspiraciones de otros muchos agricultores del resto del valle bético que aun sin aspirar a proyectos tan grandilocuentes, nunca había cejado en el empeño de llevar el agua hasta sus campos.

Para poder llevar a cabo la transformación en regadío, el cauce del río se dividió en tres grandes zonas regables, una de las cuales, la «zona alta del Guadalquivir», la más cercana al muro de la presa, se extendía por ambas márgenes del río, desde las proximidades de Mogón, un pequeño núcleo de población perteneciente a Villacarrillo, hasta el límite de los términos municipales de Úbeda y Baeza. El área regable no sólo afectaba a la cara sur de la Loma de Úbeda sino también a pequeñas porciones de otros municipios de la comarca de la Sierra de Cazorla, pero, en conjunto, la superficie regada era sensiblemente inferior a la que se había previsto transformar mediante el fracasado canal, pues tan sólo ascendía a 3.441 has. De acuerdo con el plan general de colonización de esta zona, la transformación en regadío vino acompañada de la construcción de distintos poblados de colonización en los cuales se asentaron un considerable número de colonos a los que se les entregó, además de la vivienda, un lote diminuto de tierra (Gallego Simón, 2010).

En ningún momento el agua embalsada en el Tranco se utilizó para el riego de aquellas tierras que se encontraban más cercanas al pantano. Ni siquiera la pequeña porción de la fértil vega del río Hornos que había quedado al margen de las expropiaciones, pudo regarse con esas aguas. Tampoco, obviamente, las de otros valles serranos más distantes en los que se requerían grandes inversiones para poder beneficiar sus campos con el agua embalsada. Todos ellos continuaron regándose esporádicamente por los mismos sistemas que se habían empleado durante siglos. Hasta que no se inauguró el embalse del Guadalmena en 1969, no pudo establecerse la primera zona regable de una cierta entidad en la porción más externa de la Sierra de Segura. Una historia que ha venido a repetirse recientemente, cuando la demanda de agua para riego del olivar en la porción septentrional de la comarca se ha solventado con la construcción de una nueva presa en las inmediaciones de la localidad de Siles, actualmente en ejecución.

\section{Central eléctrica}

Poco antes de que se inaugurara el pantano, a finales de 1944, se hizo público el concurso para la concesión de la explotación conjunta del aprovechamiento hidroeléctrico del salto de pie de presa del pantano y de los que en el futuro pudieran instalarse en el siguiente tramo del Guadalquivir, comprendido entre la presa y la central hidroeléctrica que explotaba la Sociedad Electra de la Fuensanta, situada a 17 kilómetros aguas debajo de aquella. La adjudicación recayó en la Compañía Mengemor, la más potente empresa eléctrica que operaba en la provincia en aquellos años (Puig, 1960), que ya se había encargado del suministro eléctrico a las obras del Tranco desde su central de Olvera. Su presencia en la provincia de Jaén se remontaba a principios del siglo XX, cuando empezó a construir distintas centrales eléctricas sobre el Guadalimar y Guadalquivir con el objetivo principal de atender al sumi- 
nistro del conjunto de instalaciones mineras situadas en el distrito Linares-La Carolina. Tan prósperos resultaron sus negocios que muy pronto consiguió la adquisición distintas fábricas de luz que venían funcionando en la provincia desde finales del siglo XIX. Inmediatamente después procedió a la transformación tecnológica de todas ellas a fin de incrementar su capacidad de producción y así poder ampliar su red de distribución y la cartera de clientes. Su mayor éxito empresarial lo alcanzó a principios de los años treinta, cuando consiguió la adjudicación de la explotación hidroeléctrica de los grandes embalses del Jándula y del Encinarejo, en los que la electricidad empezó a generarse a una escala desconocida hasta aquellas fechas. Eso le permitió a la empresa alcanzar una posición de absoluta hegemonía en el mercado eléctrico jiennense y cordobés. La nueva concesión del Tranco que ahora recibía, venía a reforzar aún más ese dominio del mercado, y auguraba una expansión de la que Mengemor esperaba obtener, sin duda, unos suculentos beneficios empresariales.

Tras la resolución del concurso en marzo de 1946, de inmediato se procedió a la construcción de la central hidroeléctrica; un aprovechamiento del agua embalsada que se había dejado entrever en el Real decreto-ley que autorizaba las obras del Tranco pero que, a no dudarlo, constituía un fin secundario frente al objetivo central de potenciación del regadío. Tanto es así que la presa carecía de tomas de agua para las turbinas de la central, como se aprestó a exponer José Luís Mendoza, el Ingeniero de Caminos que llevó a cabo la instalación (Mendoza Gimeno, 1947). Para sortear esta dificultad, dado que no podía perforarse la pared de la presa, después de barajar distintas soluciones se optó por abrir un túnel en

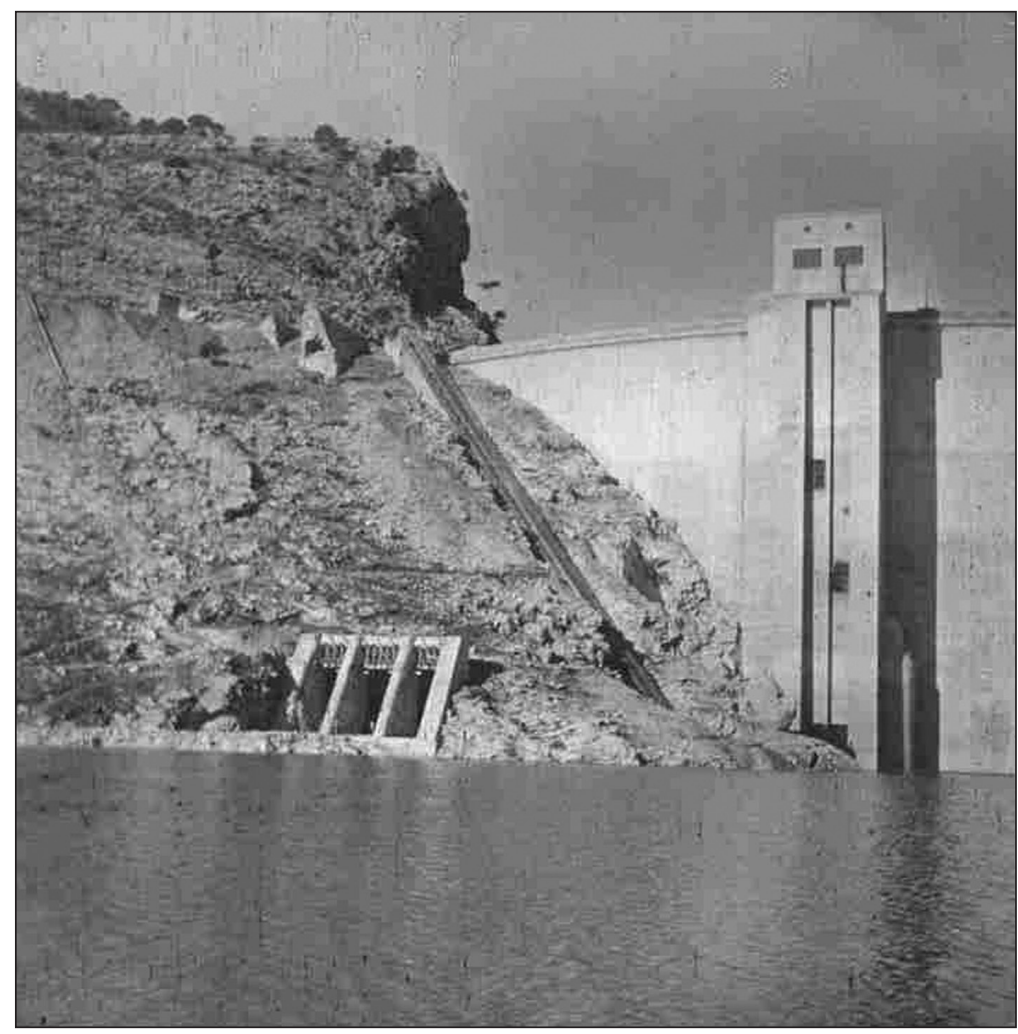

Fото 2. Toma de agua de la central eléctrica del Tranco. 
la ladera izquierda del embalse, por debajo de la cimentación del estribo, con el fin de derivar el agua de alimentación de las turbinas. Así pues, la central quedaba emplazada a pie de presa pero a 30 metros por debajo del cauce del río, con lo cual podía aprovecharse el desnivel de casi 110 metros existente a embalse lleno. La estación transformadora se situaba en superficie, sobre una pequeña llanada construida ex profeso al pie del muro de la presa. Contaba con tres grandes transformadores desde los que se distribuía la energía tanto al valle del Guadalquivir como a la región levantina.

Era esta la primera vez que se construía en España una central subterránea, lo que suponía un gran salto adelante desde el punto de vista tecnológico pero al mismo tiempo comportaba un gran desembolso económico no exento de riesgos, sobre todo si tenemos en cuenta que una gran parte de la maquinaria de la central había que importarla y no era fácil, en primer lugar, obtener la preceptiva autorización gubernamental y, en segundo lugar, disponer de las divisas necesarias para poder pagarla (Bernal, 1994). Estas y otras anomalías asociadas a las dificultades de producción que se presentaron durante las prolongadas sequías de los años cuarenta, colocaron a Mengemor en una complicada situación financiera de la que sólo pudo escapar mediante su fusión en 1951 con la Compañía Sevillana de Electricidad, que fue, a la postre, la que puso en funcionamiento la central en junio de 1953 (Sagasta Azpeitia, 1955).

Tal y como se había previsto en el momento de su construcción, la mayor parte de la energía eléctrica generada en la central se transportaba hasta la subestación de Andújar, distante más de 150 kilómetros del lugar de producción. Una vez transformada, desde estas instalaciones podía atenderse la creciente demanda urbana e industrial generada en aquella porción del territorio provincial donde empezaba a concentrarse buena parte de la actividad fabril, y en la que se registraban mayores tasas de crecimiento poblacional; llegado el caso, podían cubrirse, incluso, parte de las necesidades de las grandes ciudades del valle del Guadalquivir.

Tras la transformación de las grandes zonas regables, la energía proporcionada por el Tranco resultó fundamental para el funcionamiento de las múltiples estaciones elevadoras de agua situadas en los distintos sectores en que quedaron divididas esas zonas. Su elevado consumo eléctrico no sólo quedó asegurado en el futuro con los aportes de esta central sino que se fijaron unos precios por kilovatio consumido sumamente favorable a los agricultores, del que todavía hoy siguen beneficiándose. Las condiciones que se fijaron en el contrato de explotación firmado con la Compañía Sevillana de Electricidad obligaban a ésta, entre otras cosas, a reservar al Estado el $25 \%$ de la energía generada en la central, que la abonaría a razón de 0,10 pesetas el kilovatio hora, el mismo precio que se trasladaba después a los agricultores.

Esta situación contrastaba abiertamente con la que se registraba en una gran parte de las viviendas de la Sierra de Segura que no solo no disponían de luz eléctrica sino que aun tardarían muchos años en disponer de ella. Las pequeñas fábricas de luz que venían funcionando desde principios del siglo XX no eran capaces de mantener el suministro continuado de electricidad durante todo el día, ni de extender sus líneas más allá de los principales centros de población Para mayor agravio, ni las pequeñas aldeas, caseríos, cortijos y cortijadas que se hallaban más próximos a la central pudieron beneficiarse de la energía eléctrica producida en la misma puesto que en ningún momento se contempló el trazado de una línea hasta ellas. Una situación paradójica que demostraba hasta qué extremo despreocupaba al gobierno y a la empresa concesionaria el bienestar de los habitantes de esta comarca deprimida.. 


\section{Repoblación y corrección hidrológico-forestal de la cuenca de alimentación del embalse}

Cuando todavía faltaban algunos años para que el pantano comenzara a embalsar agua, se pusieron en marcha los trabajos de repoblación forestal de la cuenca de alimentación, profundamente deforestada después de siglos de extracciones incontroladas de arbolado y otra clase de agresiones de similar entidad: pastoreo abusivo, incendios forestales, roturaciones arbitrarias, etc. Esta actuación se consideraba imprescindible para alargar el período de vida del pantano, toda vez que las tasas de erosión que soportaban sus laderas eran muy elevadas. De no haber procedido a su corrección, a buen seguro que el vaso del pantano se hubiera entarquinado en poco tiempo, dejando completamente inservible una infraestructura hidráulica tan costosa.

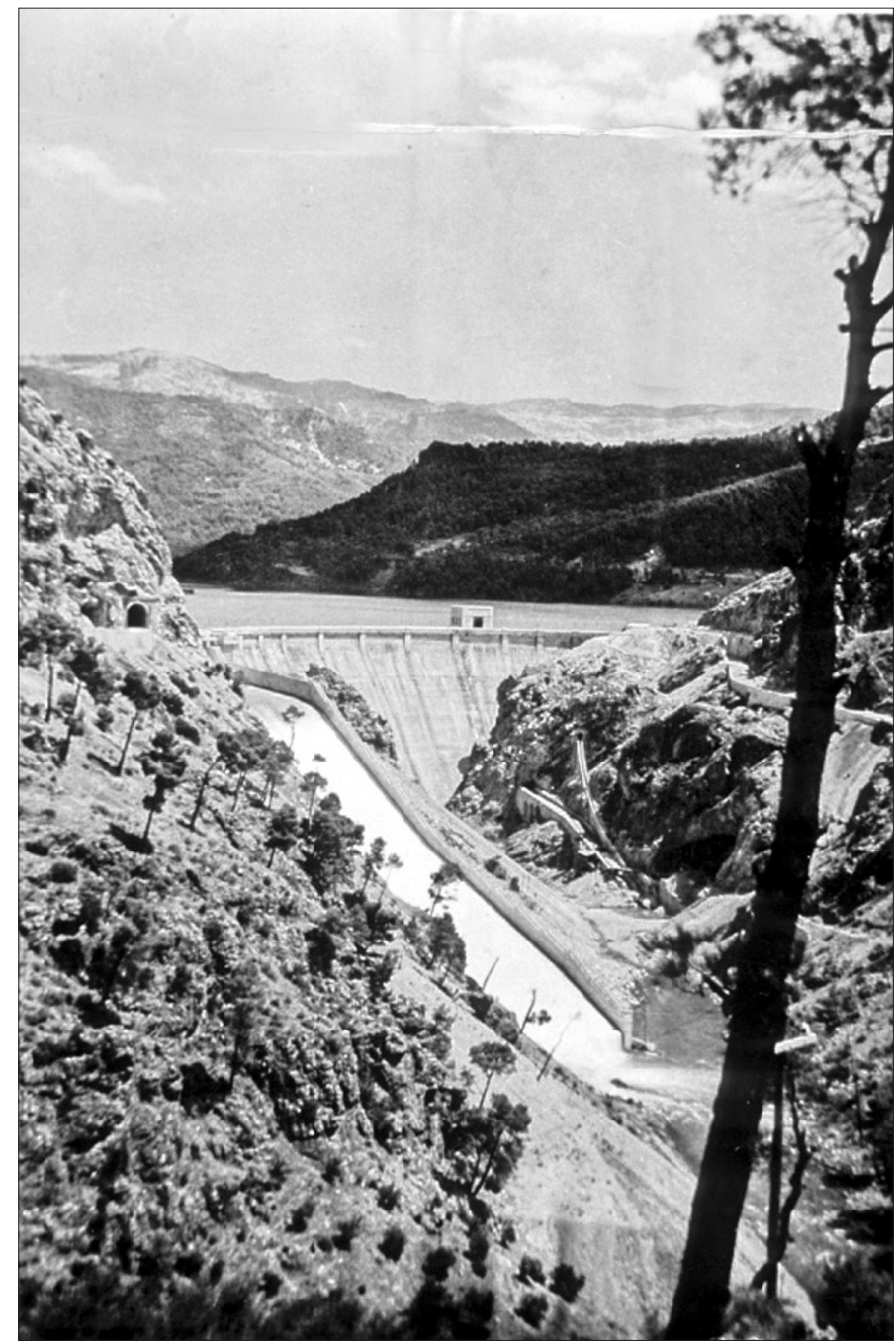

Fото 3. Deforestación de las laderas del embalse del Tranco. 
Los trabajos de repoblación se iniciaron por el Patrimonio Forestal del Estado (PFE) tras la conclusión de la guerra civil española, con una urgencia que solo podía entenderse por la inminencia del cierre del muro de la presa. En un primer momento la actuación se ciñó a aquellos rodales de los montes más próximos al embalse que pertenecían indiscutiblemente al Estado, y como tales figuraban inscritos en el Registro de la propiedad y en el Catalogo de montes de utilidad pública. Más tarde, la actuación se extendió a otras porciones de esos mismos montes en los que se contabilizaban un gran número de roturadores autorizados y arbitrarios, cuyo asentamiento se había producido en los momentos de mayor presión demográfica de la segunda mitad del siglo XIX y primer tercio del siglo XX, sin duda como respuesta a las estrictas necesidades de subsistencia de sus ocupantes.

De forma simultánea, el PFE procedió a la compra de distintos montes de titularidad privada que se hallaban enclavados en la cuenca de alimentación del pantano, cuyo estado forestal también podía calificarse de extremadamente ruinoso desde el punto de vista forestal. Entre 1941 y 1945 se adquirieron ocho montes con una cabida conjunta de 5.394,7 has., por las cuales se abonaron algo más de 4,5 millones de pesetas, o sea, a una media de 846,5 pts/ha.; un precio algo superior al que se adquirieron algunos montes vecinos pero muy inferior al promedio nacional de esos momentos (Araque Jiménez, 2009 b).

En todos los casos la venta se realizó por libre acuerdo entre las partes, sin que se presentaran grandes escollos a la hora de la tasación de los predios. Los propietarios eran conscientes de que el PFE disponía de todos los resortes legales para hacerse con el control efectivo de esos montes después de que toda esta zona fuera clasificada como «comarca de interés forestal nacional» en 1941. Semejante decisión llevaba aparejada la declaración de utilidad pública, necesidad de la ocupación y urgencia de las expropiaciones necesarias para llevar a cabo los trabajos de repoblación. Por si quedaba alguna duda, otro decreto de 1955 aplicaba esa misma fórmula jurídica a todos aquellos propietarios particulares de terrenos forestales que se hallaran desprovistos de vegetación en los términos municipales de Santiago de la Espada y Pontones, ofreciéndoles a sus titulares la posibilidad de establecer un consorcio con el PFE en los términos fijados por este organismo.

Con esta última norma se pretendía extender la repoblación forestal mucho más allá de los estrictos límites de la cuenca del embalse, para lo cual se contaba con las generosas consignaciones presupuestarias incluidas en la Ley por la que se había aprobado el ya mentado «Plan Jaén». Como un capítulo aparte del programa repoblador previsto para toda la provincia, dicho Plan destinaba 75 millones de pesetas, distribuidos en diez anualidades, a la obra de repoblación de la zona del Tranco, demostrando con ello la prioridad que los planificadores concedían a este embalse, sin duda la piedra angular sobre la que descansaban las restantes actuaciones programadas.

Hasta 1970 sólo en los montes que envolvían al pantano del Tranco, tanto los que desde antiguo pertenecían al Estado como en los de reciente adquisición, se repoblaron un total de 3.000 has. (Sánchez Martinez, 1998), a las que habría que unir las que se repoblaron en otros muchos montes de la cuenca alta del Guadalquivir, aguas arriba de las colas del embalse. Esos trabajos vinieron acompañados de numerosas obras de corrección hidrológica en algunos de los arroyos que vertían aguas directamente sobre el vaso del pantano, sobre los cuales se construyeron grandes diques de mampostería perpendiculares al cauce. De esta forma, además de limitar la capacidad erosiva del agua que corría por las empinadas laderas, se retenían los tarquines antes de que llegaran a depositarse en el vaso del pantano. Tanto las labores de plantación de arbolado como las de construcción de diques provocaron un incremento sustancial de los niveles de empleo en una zona gravemente afectada por el paro crónico de la mayor parte de su población activa. Desde ese punto de vista no cabe duda que la actuación repobladora cumplió temporalmente con el objetivo 
social de generación de empleo que se había marcado la actuación repobladora en ámbitos geográficos como el que nos ocupa.

\section{El problema social}

Tanto las expropiaciones que originó la construcción del pantano como los distintos procesos de saneamiento de la propiedad pública que trajo aparejada la repoblación forestal de su cuenca de alimentación, originaron un tremendo problema social en el que se vieron envueltos centenares de vecinos de los municipios de Hornos de Segura, Pontones y Santiago de la Espada, que de la noche a la mañana se vieron desposeídos de todos sus bienes y empujados de manera irremediable a la emigración definitiva. De muy poco sirvieron los pronunciamientos de las autoridades locales y la de algunos Ingenieros de montes reclamando una solución justa al grave problema humanitario que se había generado en esta porción de la Sierra de Segura.

La expropiación de tierras para la construcción del embalse suscitó las lógicas protestas de los afectados tanto por la tasación de los bienes afectados como por la demora a la hora de cobrar las indemnizaciones. No obstante, la inmensa mayoría de los habitantes que vivían dispersos en cortijos y cortijadas por las vegas de los ríos Hornos y Guadalquivir acabaron aceptando las condiciones impuestas y abandonaron sus tierras, emigrando en la mayoría de los casos a localidades vecinas de la Sierra de Segura o de la comarca de La Loma.

El escollo de mayor envergadura se presentó en la pequeña aldea de Bujaraiza, en la que estaban censados más de 300 habitantes en 1940, los cuales reclamaban una solución conjunta que compensara no ya sólo la pérdida de sus tierras y viviendas sino también la desaparición como tal de una entidad de población que se había ido dotando de distintos elementos de un gran simbolismo y apego personal (iglesia, cementerio, etc.). Hasta que las aguas del embalse no empezaron a cubrir la aldea, los vecinos resistieron a la espera de una solución satisfactoria para todos ellos que no llegó hasta comienzos de 1950, cuando se decidió el traslado de las 26 familias que aun residían en Bujaraiza hasta el poblado de colonización de El Calonge, situado en el valle del Guadalquivir, en las inmediaciones de la localidad cordobesa de Palma del Río. Allí se les dotó de una vivienda y de una pequeña parcela agrícola para que pudieran reiniciar sus vidas.

Mucho más complicada resultó la adopción de soluciones para los pequeños roturadores instalados en los montes públicos, todos los cuales, al margen de su situación administrativa, fueron obligados a abandonar sus parcelas agrícolas y las modestas viviendas que habían construido junto a ellas, una vez que se iniciaron los trabajos de repoblación forestal. La opción de establecer un manto forestal continuo en torno a la lámina de agua del pantano primó sobre cualquier otra consideración paisajística o ecológica en la que hubieran tenido cabida estos enclavados, tanto por su papel en la diversificación de un paisaje completamente homogéneo como por su importante función a la hora de prevenir y luchar contra los incendios forestales.

Para que nos hagamos una idea de las verdaderas dimensiones que alcanzaba el problema, baste con señalar que sólo en los montes del Estado que formaban parte de la cuenca de alimentación del embalse se contabilizaban en la inmediata posguerra más de un millar de roturadores que ocupaban una superficie cercana a las 1.600 has. (Cuadro 1). Eso significa que cada roturador disponía, por término medio, de una explotación de 1,5 has., integrada frecuentemente por varias parcelas. La situación más llamativa se registraba en distintos montes estatales localizados en el municipio de Pontones que vertían aguas al Guadalquivir, donde se concentraban un mayor número de roturadores que habían llegado a constituir, 
incluso, pequeñas aldeas de una cierta entidad poblacional. Por el contrario, los montes que había adquirido el PFE en los años cuarenta estaban, en general, exentos de este problema.

Cuadro 1

ROTURACIONES EN LOS MONTES DEL ESTADO DE LA CUENCA DE ALIMENTACIÓN DEL EMBALSE DEL TRANCO

\begin{tabular}{|c|c|c|c|c|}
\hline \multirow[b]{2}{*}{ Monte } & \multicolumn{2}{|c|}{ Roturadores autorizados } & \multicolumn{2}{|c|}{ Roturadores arbitrarios } \\
\hline & $\mathbf{N}^{\circ}$ & Has. & $\mathbf{N}^{\circ}$ & Has. \\
\hline Cerro del Romeral & 23 & 15,9 & 7 & 5,0 \\
\hline Ramblillas & 1 & 2,0 & - & - \\
\hline Cerro de las Canasteras & 4 & 4,1 & 27 & 97,8 \\
\hline Desde Aguamula hasta... & 9 & 5,1 & 295 & 378,1 \\
\hline Malezas de Pontones & - & - & 65 & 106,8 \\
\hline Montalvo y Hoya Morena & 12 & 11,5 & 134 & 214,5 \\
\hline Peña Amusgo & - & - & 76 & 176,5 \\
\hline Poyo Segura de Pontones & - & - & 67 & 236,1 \\
\hline Malezas de las Campanas & 8 & 2,9 & 51 & 70,2 \\
\hline Malezas de Santiago & 25 & 18,8 & 85 & 106,3 \\
\hline Poyo Segura de Santiago & 21 & 26,7 & 12 & 8,1 \\
\hline Torre del Vinagre & 3 & 1,6 & - & - \\
\hline La Hortizuela del Guadalquivir & 43 & 46,3 & - & - \\
\hline Aguas Blanquillas & 8 & 6,5 & - & - \\
\hline Solana de Coto Ríos & 6 & 1,8 & - & - \\
\hline Bujaraiza & - & - & 2 & 0,4 \\
\hline San Roman & - & - & - & - \\
\hline Cabeza de la Viña & - & - & - & - \\
\hline Fuente del Roble & 3 & 0,3 & 28 & 38,7 \\
\hline Total & 166 & 143,5 & 849 & $1.438,5$ \\
\hline
\end{tabular}

Fuente: González Aguilar (1961). Citado en bibliografía.

En su inmensa mayoría (83,6 \% de los roturadores y 90,9\% de la superficie poseída) se trataba de roturadores arbitrarios que habían ocupado esas tierras al margen de cualquier mecanismo legal y sin ninguna autorización para ello por parte de la Administración forestal. Simplemente habían roturado una pequeña fracción de monte y se habían asentado en ella con toda su familia. A su lado coexistía un pequeño grupo de roturadores autorizados que anualmente satisfacían un canon a la Administración por la ocupación de los montes; canon que variaba en función de la superficie poseída y de la clasificación de la roturación en secano o regadío. 
A estos últimos, simplemente se les desahució, advirtiéndoles con antelación de la caducidad de la autorización administrativa de la que disfrutaban. En los contratos de arrendamiento que se habían efectuado con cada roturador se establecía que el usufructuario debía abandonar la parcela en el momento en que le interesara a la Administración forestal, dejando ésta arada y cavada, sin percibir por ello ningún tipo de indemnización (Araque Jiménez, Gallego Simón y Moya García, 1992). En consecuencia la supresión de este tipo de roturaciones no planteó ningún problema legal pero sin generó un tremendo conflicto social.

A los roturadores arbitrarios, en cambio, se les expulsó directamente de los montes, privándoseles de las ínfimas parcelas que habían cultivado durante años y de las modestas viviendas en las que residían. Como la ocupación se había hecho al margen de cualquier mecanismo legal, no podía considerárseles oficialmente como propietarios de un bien que no les pertenecía. Por consiguiente, la Administración forestal se eximió de plantear algún tipo de solución que pudiera paliar la grave situación a la que se enfrentaban los roturadores. Con el transcurso de los años, a medida que la repoblación forestal de la cuenca de alimentación se fue extendiendo por nuevos montes y, sobre todo, desde que a mediados de 1960 todos ellos quedaron englobados en el Coto Nacional de Caza de las Sierras de Cazorla y Segura que se creó en esos momentos (Crespo Guerrero, 2003), el problema alcanzó tintes verdaderamente dramáticos que obligaron a la Administración forestal a modificar su forma de actuación. Un solo dato puede ayudarnos a percibir la dimensión humanitaria que planteaba el asunto: en el monte Desde Aguamula hasta el Arroyo de las Espumaredas, donde se contabilizaban 295 roturadores arbitrarios, residían junto a ellos un total de 969 personas que formaban parte de sus numerosas familias. En el resto de los montes se registraban proporciones similares de familiares de todas las edades a cargo de los roturadores, todo lo cual confería al problema ese dramatismo al que nos referimos.

Este problema no pasó desapercibido entre algunos de los Ingenieros de montes que visitaron la zona en ese momento por diferentes motivos. González Aguilar, que redactaba durante aquellos años su proyecto fin de carrera, entendía que no se debía acabar con las roturaciones de forma violenta. Eso condenaba a los roturadores al abandono de sus medios de vida, y «no era razonable ni humano, aunque lo abone la estricta aplicación de los artículos de la legislación, desposeer a tan numerosas familias de tierras y viviendas en la seguridad de que muchas serán así lanzadas a una situación peor; o también, pues otros viven miserablemente, a una mayor miseria» (González Aguilar, 1961).

Los Ayuntamientos de Santiago de la Espada y de Pontones se quejaron reiteradamente ante las máximas autoridades nacionales y provinciales del grave quebranto que estaba ocasionando a muchos vecinos esta drástica intervención estatal. A mediados de 1947, por fin, consiguieron una respuesta a sus peticiones que les llegó a través de una Orden del Ministerio de Agricultura en la que se mandaba formar una comisión que se encargaría de dictaminar sobre todas las reclamaciones posesorias planteadas por el vecindario en aquellos montes donde se estaba llevando a cabo la repoblación forestal. Después de una notable dilación, la comisión pudo comprobar a finales de 1950 que la inmensa mayoría de los documentos posesorios esgrimidos por los detentadores no tenían ningún valor jurídico (Araque Jiménez, 1986). Ni siquiera las escrituras de propiedad o los documentos que trataban de acreditar una posesión ininterrumpida durante más de treinta años podían considerarse validos a efectos legales toda vez que no estaban a nombre de los demandantes.

Así las cosas, todas las partes implicadas convinieron en que la solución al problema de los roturadores arbitrarios pasaba por la intervención del Instituto Nacional de Colonización, que desde 1953, en el marco del «Plan Jaén», había acelerado considerablemente las obras de transformación en regadío y construcción de nuevos núcleos de población en 
la porción jiennense del valle del Guadalquivir. De un modo similar a como se había hecho con los habitantes de Bujaraiza, a una parte de los afectados se les ofreció la posibilidad de trasladarse a esos poblados de colonización en las mismas condiciones que el resto de los agricultores que se beneficiaron de esa política, esto es, asignándoles una vivienda que, desde luego, reunía mejores condiciones de habitabilidad que las que dejaban atrás, y una parcela agrícola de diferente dimensión según el poblado y la categoría del colono. Algunos de ellos finalmente acabaron aceptando el traslado (Gallego Simón, Sánchez Martínez y Araque Jiménez, 2003), mientras que otros optaron por la emigración definitiva a distintas regiones del centro y norte peninsular, o bien a aquellas ciudades jiennenses en las que existían mayores perspectivas laborales tanto para el cabeza de familia como para la numerosa prole que lo acompañaba en el destierro.

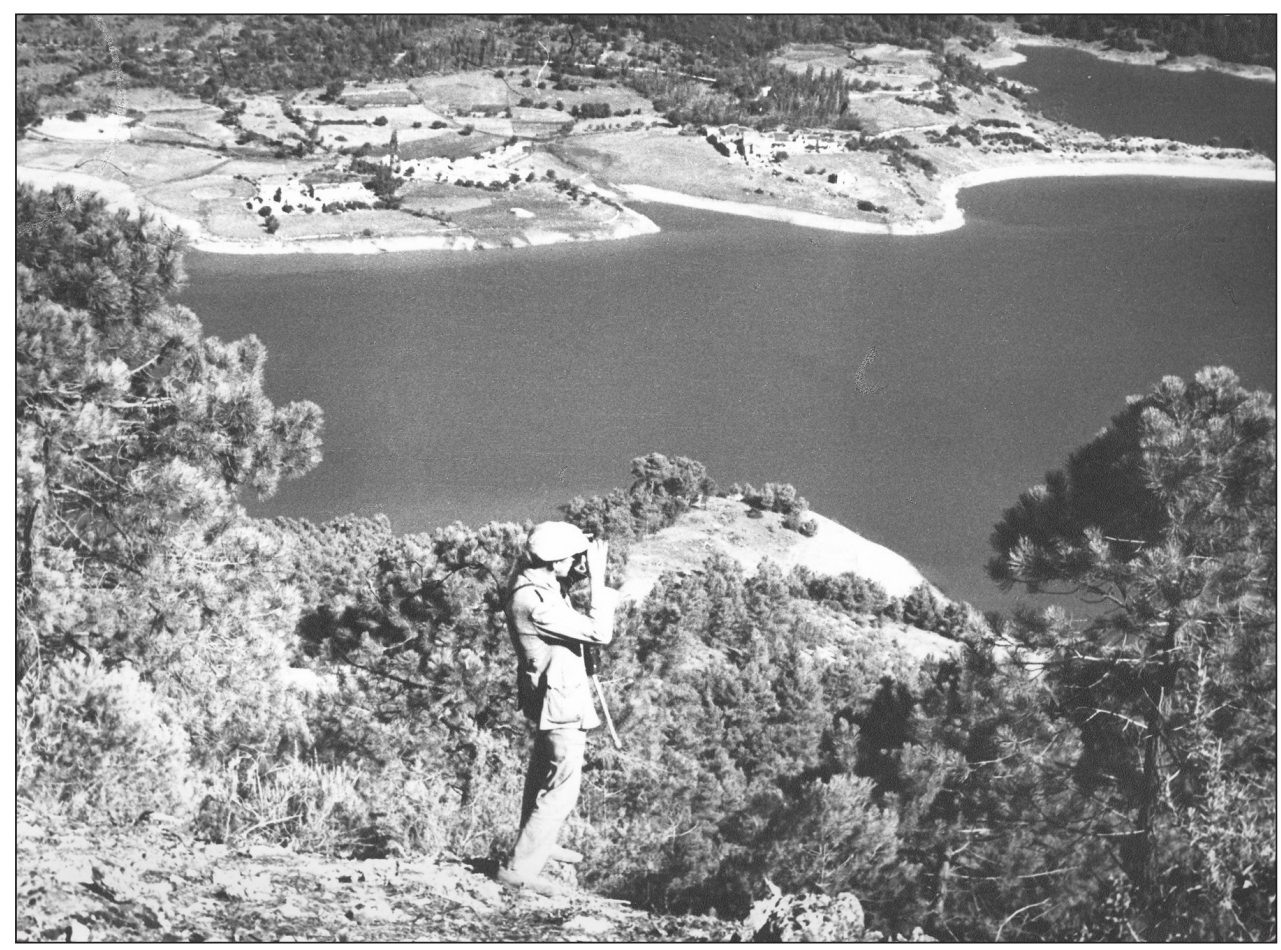

Foтo 4. Aldea de Bujaraiza.

Este paulatino proceso de abandono de los montes, aparte de otras connotaciones territoriales, planteaba dos graves inconvenientes de los que eran plenamente conscientes los Ingenieros de montes que dirigieron los trabajos de repoblación forestal. Por un lado, dejaba de disponerse de la mano de obra necesaria para afianzar las plantaciones forestales que, como se sabe, requieren de continuados cuidados culturales durante los primeros años de crecimiento del arbolado. Este inconveniente era tanto más grave por cuanto toda esta zona montañosa se encontraba profundamente aislada, sin carreteras que la comunicaran con los núcleos urbanos más próximos, atravesada solo por algunas vías de saca que en esos momentos se hallaban en construcción (Simón, 1951; Cerda, 1953). A lo anterior 
se unía la carencia de medios de locomoción personales entre la inmensa mayoría de los trabajadores, lo cual les impedía desplazarse hasta los lugares de trabajo en los montes.

Por otra parte, la proliferación de pinos con densidades muy elevadas de pies por hectárea, incrementaba el riesgo de incendios en los montes a pesar de haber desaparecido muchas de las causas imputables a la intencionalidad o a la negligencia humana. Históricamente ya se había podido demostrar en esta misma zona, muy castigada por el fuego (Araque Jiménez et al., 2000), que la presencia de un importante contingente de población en las inmediaciones de las masas arboladas constituía un elemento esencial en la lucha contra el fuego puesto que permitía atacar las llamas antes de que éstas se expandieran y alcanzaran un gran desarrollo superficial. Además, los campos de cultivo que circundaban las pequeñas aldeas, cortijos y cortijadas actuaban como cortafuego que impedía el avance de los incendios. Ahora, sin esta presencia, la eficacia en la lucha contra el fuego corría el riesgo de disminuir, lo que suponía una seria amenaza para la masa forestal creada en torno al pantano que corría el riesgo de desaparecer si se desencadenaba un gran incendio.

Para remediar, en parte, las aciagas consecuencias de la despoblación y el despoblamiento que había sucedido a la repoblación forestal, en 1968 se creó un nuevo núcleo de población en la cola del embalse del Tranco, Coto Ríos, que se ocupó con los últimos roturadores que fueron obligados a abandonar los montes. Del mismo modo que se había hecho en los poblados de colonización, a cada uno de los cabezas de familia que se instalaron en el nuevo poblado se le asignó una vivienda y un pequeño huerto agrícola localizado en las inmediaciones del casco urbano con el fin de que pudieran procurarse sus alimentos vegetales durante una parte del año. Algunos de los roturadores instalados pasaron a formar parte de la plantilla de guardas forestales, cuyos efectivos se incrementaron tras la creación del Coto Nacional de Caza, mientras que el resto se ocuparon en los diferentes trabajos de conservación que requerían los montes, incluida la vigilancia y lucha contra el fuego.

\section{Conclusiones}

Durante muchos años el embalse del Tranco constituyó una pieza clave de la política hidráulica andaluza. Gracias a sus aguas pudieron regarse de forma permanente los sedientos campos de cultivo del valle del Guadalquivir, el ámbito geográfico más fértil de la región, y diversificarse el monótono mapa de cultivos agrícolas. Desde luego sus aportaciones hídricas resultaron fundamentales para el sostenimiento de la política de colonización que con tanto brío se impulsó en ese ámbito a partir de los años cincuenta. Aunque los grandes beneficiados por ésta fueron los medianos y grandes propietarios de cada una de la nuevas zonas regables, no cabe duda que muchos pequeños campesinos y jornaleros sin tierra condenados a la exclusión social también se beneficiaron de ella y pudieron reiniciar sus vidas en condiciones mucho más dignas.

La otra cara de la moneda nos la ofrece la Sierra de Segura, especialmente su porción más meridional en la que se halla emplazado el embalse. Aparte de los beneficios coyunturales que se obtuvieron en forma de empleo de la mano de obra mientras duró la construcción del muro de la presa, muy pocas ventajas más se derivaron de la presencia de una enorme lámina de agua que anegó las mejores tierras de cultivo e hizo desaparecer para siempre centenares de cortijos y cortijadas en las que secularmente habían residido un buen número de vecinos. La repoblación forestal que acompañó a la creación del embalse, como un elemento absolutamente indispensable del mismo, ahondó aun más en el problema social inicialmente generado al propiciar la erradicación de miles de roturaciones y roturadores a los que no siempre se ofertaron salidas airosas sino que se les empujó directamente a la emigración en condiciones de una precariedad extrema. 
Para mayor escarnio, las aguas embalsadas en el Tranco no contribuyeron a solventar ninguno de los problemas más acuciantes que tenía planteados la Sierra de Segura en la inmediata posguerra. La transformación de la agricultura mediante la introducción del regadío a gran escala no fue posible porque en ningún momento, ni siquiera tras las generosas dotaciones económicas del «Plan Jaén», se planteó la constitución de una gran zona regable en las proximidades del embalse que presentaban una mayor aptitud para esta modificación. A buen seguro que ello hubiera contribuido a la necesaria diversificación agrícola y, sobre todo, a una mayor complementariedad entre agricultura y ganadería, otro de los grandes pilares de la economía rural serrana. Tampoco la generación de electricidad en la central situada a pie de presa vino a mejorar las difíciles condiciones de existencia de la inmensa mayoría de los hogares de la Sierra de Segura, que durante muchos años continuaron careciendo de este servicio elemental

\section{Bibliografía}

ALDAZ MUGUIRO, L. (1945): La impermeabilización por inyecciones del embalse del Tranco. Revista de Obras Públicas. N 2762. Págs. 234-239.

ANGUIS DIAZ, A. (1933): Canal alto de la Loma de Úbeda con las aguas del Guadalquivir que se embalsan en el pantano que se construye en el Portillo del Tranco de Beas. Original mecanografiado.

ARAQUE JIMÉNEZ, E. (1986): Utilización del suelo y conflictividad social en la Sierra de Segura tras la guerra civil, en Actas del III Coloquio Nacional de Geografía Agraria. Cáceres. Publicaciones de la Universidad de Extremadura. Págs. 47-53.

ARAQUE JIMÉNEZ, E. (2007): Conducciones fluviales de madera desde las Sierras de Segura y Cazorla (1894-1949). Cuadernos Geográficos. No 40-1. Págs. 81-105.

ARAQUE JIMÉNEZ, E. (2009 a): Madera para RENFE. El aprovisionamiento ferroviario de madera en los montes españoles (1942-1953). Cuadernos Geográficos. No 44. Págs. 51-78.

ARAQUE JIMÉNEZ, E. (2009 b): Refundición de dominios y repoblación forestal en la porción andaluza de la cuenca del río Guadalentín. Investigaciones Geográficas. $\mathrm{N}^{\mathrm{o}}$ 48. Págs. 9-37.

ARAQUE JIMÉNEZ, E. Y GALLEGO SIMÓN, V. J. (2007): La Asamblea Magna Provincial de 1925. Una oportunidad perdida para el desarrollo de la provincia de Jaén, en Rodríguez Martínez, F. (Coord.): Desarrollo regional y territorio. Nuevos planteamientos y perspectivas. Granada. Instituto de Desarrollo Regional. Págs. 51-68.

ARAQUE JIMÉNEZ, E., GALLEGO SIMÓN, V.J. Y MOYA GARCÍA, E. (1992): Roturaciones y roturadores en la Sierra de Cazorla a finales del siglo XIX. Anuario del Adelantamiento de Cazorla. Nos. 33-34. Págs. 141-146.

ARAQUE JIMÉNEZ, E. ET AL. (2000): Jaén en llamas. Presencia histórica de los incendios forestales en los montes provinciales. Jaén. Instituto de Estudios Giennenses.

ARAQUE JIMÉNEZ, E. ET AL. (2006): Balance de la actuación del Instituto Nacional de Colonización en la provincia de Jaén. Investigaciones Geográficas. № 41. Pás. 15-32.

BELLO, L. (1929): Viaje por las escuelas de España. Vol. IV. Madrid. Compañía IberoAmericana de Publicaciones.

BERNAL, A. M. (1994): Historia de la Compañía Sevillana de Electricidad (1894-1983), en AA.VV.: Compañía Sevillana de Electricidad. Cien años de historia. Sevilla. Fundación Sevillana de Electricidad. Págs. 161-271.

BRIONES BLANCO, F. (1946): El pantano del Tranco de Beas. Revista de Obras Públicas. No 2773. Págs. 211-219; No 2774. Págs. 264-273. 
CALATAYUD GINER, S. (2002): Tierras inundadas: el cultivo del arroz en la España contemporánea (1800-1936). Revista de Historia Económica. № 20-1. Págs. 39-80.

CERDA, J. M. DE LA (1953): Estudio económico de las vías de saca en las Sierras de Cazorla y Segura (Jaén). Montes. № 53. Págs. 435-440.

CRESPO GUERRERO, J. M. (2003): Repercusiones sociales de los daños producidos por la repoblación cinegética de los años cincuenta en las Sierras de Cazorla y Segura (Jaén). Cuadernos de la Sociedad Española de Ciencias Forestales. № 16. Págs. 303-308.

GALLEGO SIMÓN, V.; SÁNCHEZ MARTÍNEZ, J.D. Y ARAQUE JIMÉNEZ, E. (2003): Las conexiones entre las políticas forestal y de colonización agraria en el Alto Guadalquivir, en García Marchante, J.S. y Vázquez Varela, C. (Coods): Las relaciones entre las comunidades agrícolas y el monte. Coloquio hispano-francés de geografía rural. Cuenca. Ediciones de la Universidad de Castilla-La Mancha. Págs. 77-92.

GALLEGO SIMÓN, V. J. (2010): Transformación en regadío, colonización y desarrollo rural en la provincia de Jaén. Cincuenta años de planificación territorial frustrada (19251975). Universidad de Jaén. Tesis doctoral inédita.

GIL OLCINA, A. (2001): Del Plan general de 1902 a la planificación hidrológica. Investigaciones Geográficas. No 25. Págs. 5-31.

GONZÁLEZ AGUILAR, M. (1961): Estudio estadístico y económico-social de la población instalada en los montes del Estado de las Sierras de Cazorla y Segura. Proyecto fin de carrera. Escuela Técnica Superior de Ingenieros de Montes. Universidad Politécnica de Madrid.

LOZANO MUÑOZ, F. (1867): Crónica de la provincia de Jaén. Madrid. Rubio y Cia.

MENDOZA GIMENO, J. L. (1947): El aprovechamiento hidroeléctrico del pantano del Tranco de Beas. Revista de Obras Públicas. No 2781. Págs. 1-8; № 2782. Págs. 80-82.

MESA, P. A. DE (1864): Reconocimiento hidrológico del valle del Guadalquivir. Madrid. Imprenta de Rafael Anoz.

PUIG, I. (1960): El Plan Jaén. Descripción de lo que es y será la provincia de Jaén. Barcelona. Ifiba.

RODRÍGUEZ MARTÍNEZ, F. (1981): Notas sobre la crisis y las posibilidades de desarrollo de la montaña mediterránea andaluza: el caso de Sierra Nevada. Cuadernos Geográficos. $\mathrm{N}^{\mathrm{a}}$ 11. Págs. 267-282.

SAGASTA AZPEITIA, L. M. (1955): La presa y la central del Tranco de Beas. Revista de Obras Públicas. № 2880. Págs. 163-166.

SÁNCHEZ MARTÍNEZ, J. D. (1998): La política forestal en la provincia de Jaén. Una interpretación de la actuación pública durante la etapa de administración centralizada (1940-1984). Jaén. Diputación provincial.

SIMÓN, E. DE (1951): Vías de saca en la Sierra de Cazorla. Montes. No 39. Págs. 172-178.

SPEYSER, L. G. (1858): Memoria del canal de riego de la Loma de Úbeda en la provincia de Jaén. Baeza. Imprenta de la Comisión General de Libros

TRESACO CALVO, J. (1968): Flotaciones de traviesas por ríos de Andalucía. Montes. $\mathrm{N}^{\circ}$ 141. Págs. 261-267. 
